\title{
KARAKTERISASI RESERVOIR KARBONAT DENGAN MENGGUNAKAN METODE AVO INVERSISTUDI KASUS LAPANGAN “NGAWEN”
}

\author{
Putri Rida Lestari $^{1)}$, Dwa Desa Warnana ${ }^{1)}$, Farid Marianto ${ }^{2)}$ \\ ${ }^{1}$ Teknik Geofisika, Fakultas Teknik Sipil dan Perencanaan, Institut Teknologi Sepuluh Nopember \\ ${ }^{2}$ Pgn. Saka Indonesia Pangkah Ltd. Gedung Energi lantai 11-12, SCBD Lot.11A \\ lestariputririda@gmail.com
}

\begin{abstract}
Abstrak. Kebutuhan minyak dan gas bumi semakin meningkat, sehingga diperlukan adanya peningkatan eksplorasi hidrokarbon. Eksplorasi hidrokarbon bertujuan untuk mengetahui persebaran hidrokarbon pada reservoir. Karakteristik dari batuan reservoir sangat penting diketahui untuk mendapatkan reservoir yang bagus. Salah satu metode untuk mengetahui karakteristik batuan reservoir yaitu AVO (Amplitude Versus Offset) Inversi. Metode AVO juga bisa digunakan untuk mengetahui persebaran litologi. Dalam penelitian ini digunakan metode AVO Inversi, untuk mengetahui karakteristik reservoir pada batuan karbonat, persebaran litologi, dan persebaran hidrokarbon dengan studi kasus di lapangan Ngawen. Data yang digunakan dalam penelitian ini yaitu data seismik berupa Pre-stack gather 3D di area North East Java Basin, dan dua data sumur (sumur Ngawen 1 dan sumur Ngawen 2). Penelitian ini difokuskan pada Formasi Ngimbang Karbonat. Hasil analisis crossplot menunjukkan bahwa parameter log gamma ray, $P$ impedace, S-Impedance, dan Lambda Mu-Rho (LMR) dapat mengidentifikasi litologi (porous carbonate, tight carbonate, dan shale) dan fluida (oil, gas, dan water) dengan baik. P-Impedance dan Lambda MuRho (LMR) hasil AVO Inversi menunjukkan adanya zona reservoir dan fluida hidrokarbon pada porous carbonate dengan baik. Zona reservoir karbonat ditunjukkan dengan nilai $P$-Impedance dan nilai Lambda Mu-Rho (LMR) yang relatif tinggi. Zona fluida hidrokarbon memiliki nilai $P$-Impedance dan nilai LMR yang rendah.
\end{abstract}

Kata Kunci: AVO Inversi, Formasi Ngimbang Karbonat, Lambda Mu-Rho, P-Impedance, Reservoir Karbonat.

\begin{abstract}
The need for Oil and gas is increasing, so there is a need for increased hydrocarbon exploration. Exploration of hydrocarbons to determine the spread of hydrocarbons in the reservoir. Characteristics of reservoir rocks are essential for a good reservoir. One method to know the characteristics of reservoir rock is AVO (Amplitude Versus Offset) Inversion. AVO Inversion method can also be used to determine the spread of lithology. In this study used AVO Inversion method, to find out the reservoir characteristics in Carbonate rock, to know the spread of lithology, and spread of hydrocarbons with case studies in Ngawen field. The data used in this research is seismic data Pre-stack gather 3D areas in the North East Java Basin region, and two well data (Ngawen 1 well and Ngawen 2 well). This research is focused on Ngimbang Carbonate formation. The results of crossplot analysis show that gamma ray, P-impedace, S-Impedance, and Lambda Mu-Rho (LMR) log parameters can lead to lithology (porous carbonate, tight carbonate, and shale) and fluids (oil, gas, and water). P-Impedance and Lambda Mu-Rho (LMR) result of AVO Inversion show reservoir zone and hydrocarbon fluid in the porous carbonate well. The Carbonate reservoir zone has relatively high P-Impedance and Lambda MuRho (LMR) values. The hydrocarbon fluid zone has low P-Impedance and LMR values.
\end{abstract}

Keywords: AVO Inversion, Ngimbang Carbonate Formation, Lambda Mu-Rho (LMR), P-Impedance, Reservoir Carbonate.

\section{PENDAHULUAN}

Kebutuhan minyak dan gas bumi semakin meningkat, sehingga diperlukan adanya peningkatan eksplorasi hidrokarbon. Eksplorasi hidrokarbon bertujuan untuk mengetahui persebaran hidrokarbon pada reservoir. Karakteristik dari batuan reservoir sangat penting diketahui untuk mendapatkan reservoir yang bagus. Salah satu metode untuk mengetahui karakteristik batuan reservoir yaitu AVO Inversi. Metode AVO inversi merupakan proses inversi data seismik angle gather dengan melibatkan pengaruh wavelet untuk menghasilkan secara langsung parameter fisik batuan P-Impedance (Zp), S- 
Impedance (Zs) dan Density untuk kemudian ditransformasi menjadi parameter Lambda-Mu-Rho (Hampson and Russel, 2008). Lambda-rho $(\lambda \rho)$ yang juga dikenal sebagai incompressibility digunakan sebagai indikator porositas fluida, mengandung hidrokarbon dan Mu-rho $(\mu \rho)$ yang dikenal sebagai rigiditas yang dapat digunakan untuk indikator batuan dimana parameter ini sensitif terhadap karakter matrik batuan (Gray and Andersen, 2001). Oleh sebab itu, dalam penelitian ini digunakan metode AVO (Amplitude Versus Offset) Inversi yang diterapkan pada reservoir karbonat.

Tujuan dari penelitian ini adalah untuk mengetahui karakteristik reservoir karbonat, menentukan persebaran reservoir karbonat, dan menentukan persebaran hidrokarbon di lapangan Ngawen.

Lokasi penelitian berada pada Cekungan Jawa Timur Utara (North East Java Basin), zona warna kuning (Gambar 1). Pada Gambar 1 daerah yang ada di dalam lingkaran merah merupakan lokasi lapangan Ngawen, dimana lapangan Ngawen adalah lapangan atau daerah yang dilakukan penelitian.

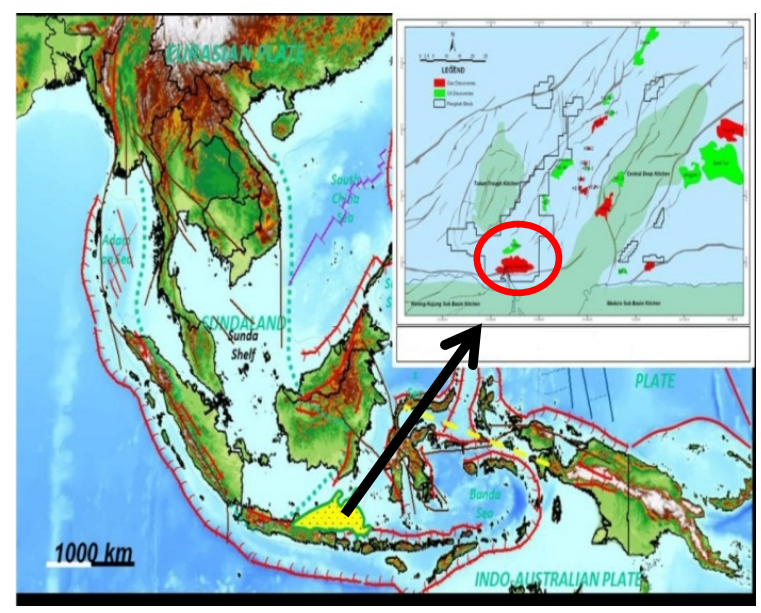

Gambar 1. Peta Daerah Penelitian (Diky Setiawan dkk, 2015).

\section{METODOLOGI}

Alur pengerjaan penelitian ini dapat kita lihat dalam diagram alir penelitian seperti pada Gambar 2. Dalam penelitian ini digunakan data seismik prestack gather 3D dan dua buah data sumur vertikal.

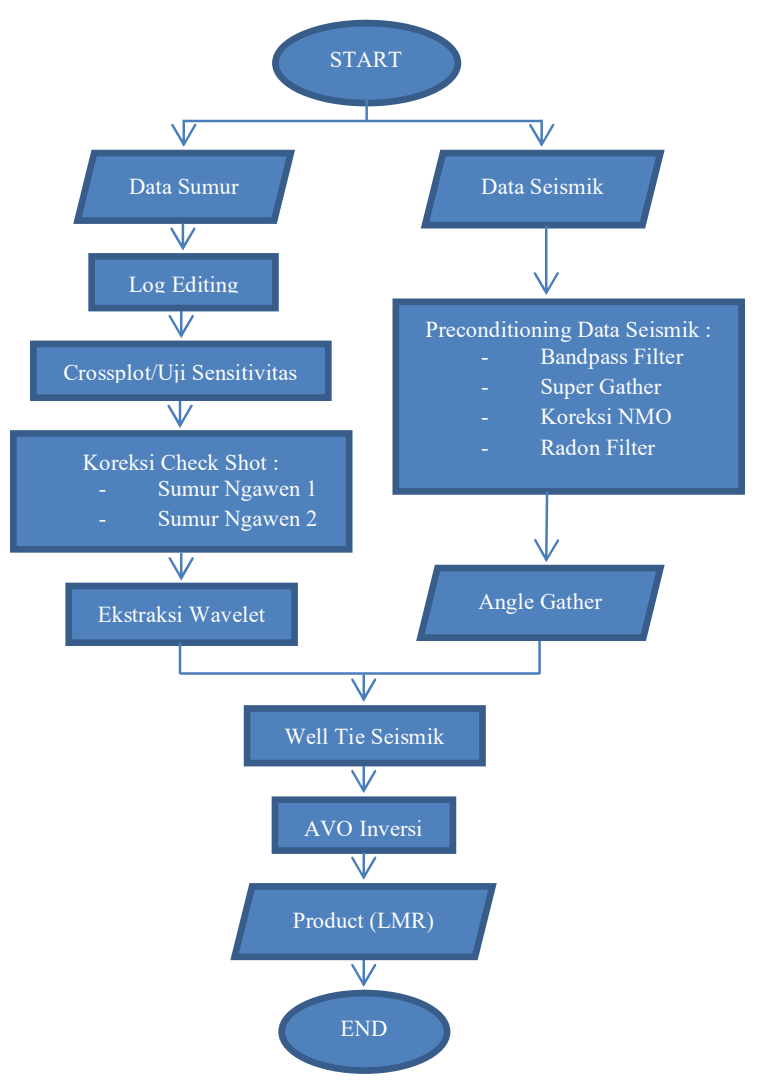

Gambar 2. Diagram Alir Penelitian.

Dua buah sumur vertikal yang digunakan dalam penelitian ini yaitu Sumur Ngawen 1 dan Ngawen 2. Berikut informasi masing-masing data sumur yang tersaji pada Tabel 1:

Tabel 1. Informasi Data Sumur.

\begin{tabular}{|l|c|c|}
\hline LOG & Ngawen 1 & Ngawen 2 \\
\hline Gamma-Ray & $\sqrt{ }$ & $\sqrt{ }$ \\
\hline Density & $\sqrt{ }$ & $\sqrt{ }$ \\
\hline P-Wave & $\sqrt{ }$ & $\sqrt{ }$ \\
\hline S-Wave & $\sqrt{ }$ & $\sqrt{ }$ \\
\hline NPHI & $\sqrt{ }$ & $\sqrt{ }$ \\
\hline Resistivity & $\sqrt{ }$ & $\sqrt{ }$ \\
\hline Check Shot & $\sqrt{ }$ & $\sqrt{ }$ \\
\hline
\end{tabular}

Dari Tabel 1, log yang akan digunakan untuk proses log editing adalah log density dan velosity. Selanjutnya dilakukan proses koreksi check shot pada Sumur Ngawen 1 dan Sumur Ngawen 2.

Data seismik yang digunakan berupa data seismik pre-stack gather $3 D$ yang belum dilakukan proses apapun. Kemudian data seismik tersebut akan dilakukan proses pre-conditioning data seismik 
untuk menghilangkan noise sehingga siap untuk dilakukan proses AVO Inversi.

Tahap pre-conditioning meliputi proses bandpass filter, super gather, koreksi NMO, dan radon filter. Bandpass filter digunakan untuk menghilangkan noise (frekuensi yang tidak diinginkan), sehingga data seismik terlihat lebih bersih dari pada sebelum dilakukan proses bandpass filter. Super gather digunakan untuk meningkatkan signal to noise ratio. Koreksi NMO digunakan untuk menghilangkan efek move out, sehingga sinyal seismik yang awalnya berbentuk melengkung ke bawah menjadi lurus searah dengan bertambahnya offset. Radon filter digunakan untuk menghilangkan multiple.

Tahapan selanjutnya adalah mengubah fungsi jarak dalam offset kedalam sudut, yaitu dengan melakukan proses angle gather, sehingga menghasilkan data Angle Gather seperti Gambar 3 di bawah ini :

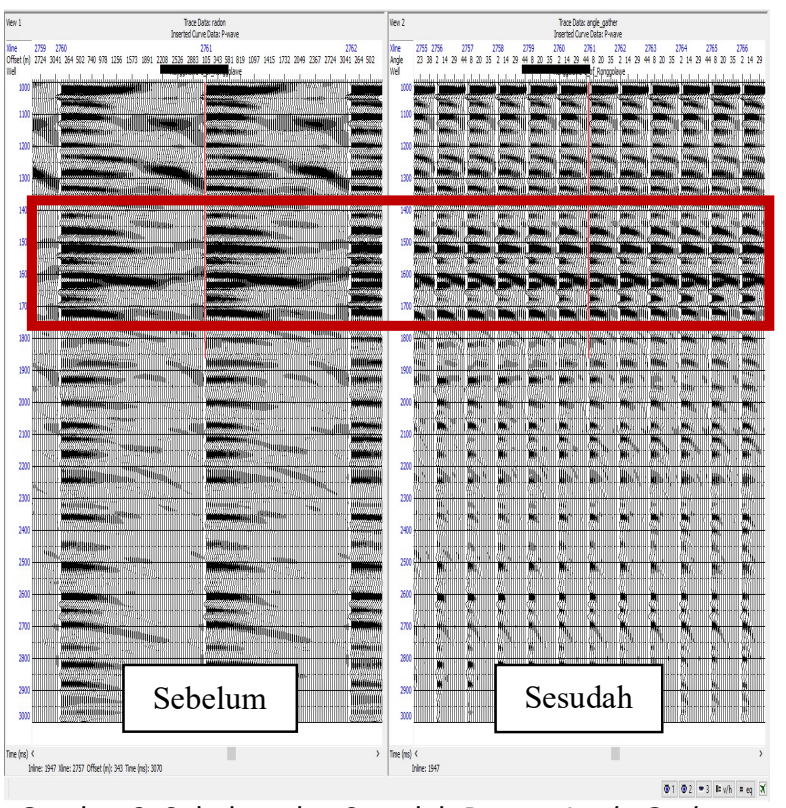

Gambar 3. Sebelum dan Sesudah Proses Angle Gather.

Gambar 3 merupakan data angle gather yang fungsi jaraknya sudah berubah ke dalam sudut (angle). Garis merah merupakan zona target dalam penelitian, yang terletak pada time domain $1400-$ $1900 \mathrm{ft} / \mathrm{s}$.

Data Angle Gather, selanjutnya dilakukan proses AVO analisis dan AVO inversi. Hasil AVO
Inversi berupa penampang $\mathrm{Zp}(P$-Impedance $)$, dan penampang LMR (Lambda Mu-Rho).

\section{HASIL DAN PEMBAHASAN}

Dari penelitian ini dihasilkan crossplot, penampang Zp ( $P$-Impedance), dan penampang LMR (Lamda Mu-rho).

Hasil crossplot antara log Gamma Ray dan Impedance bisa mengambarkan litologi dengan nilai cut off berbeda disetiap parameter. Cut off merupakan batas nilai yang dimiliki setiap parameter, untuk mengambarkan suatu obyek. Litologi yang dimaksud dalam penelitian ini yaitu batuan tight carbonate, batuan porous carbonate, dan batuan shale.

Gambar 4 merupakan hasil crossplot antara Gamma Ray dengan P-Impedance pada sumur Ngawen 1. Pada Gambar 4 batuan shale disimbolkan dengan warna hijau, dengan nilai Gamma Ray tinggi (cut off $>60 \mathrm{API}$ ), karena zona tersebut memiliki nilai porositas yang sangat tinggi. Sedangkan batuan karbonat memiliki nilai Gamma Ray yang rendah (cut off <60API). Batuan karbonat sendiri diklasifikasikan menjadi 2, yaitu batuan tight carbonate dan batuan porous carbonate. Batuan tight carbonate disimbolkan dengan warna biru, yang memiliki nilai $P$-Impedance tinggi yaitu $>33000$ $\left((\mathrm{ft} / \mathrm{s})^{*}(\mathrm{~g} / \mathrm{cc})\right)$, serta nilai porositas yang rendah. Sedangkan batuan porous carbonate disimbolkan dengan warna merah, yang memiliki nilai $P$ Impedance yang relatif rendah yaitu antara 30600$33000\left((\mathrm{ft} / \mathrm{s})^{*}(\mathrm{~g} / \mathrm{cc})\right)$, serta nilai porositas yang relatif tinggi dari pada batuan tight carbonate. Nilai P-Impedance $33000\left((\mathrm{ft} / \mathrm{s})^{*}(\mathrm{~g} / \mathrm{cc})\right)$ merupakan nilai cut off atau nilai pembatas yang bisa dijadikan pembeda untuk batuan tight carbonate dengan porous carbonate, karena pada nilai tersebut terlihat perbedaan nilai porositasnya. 


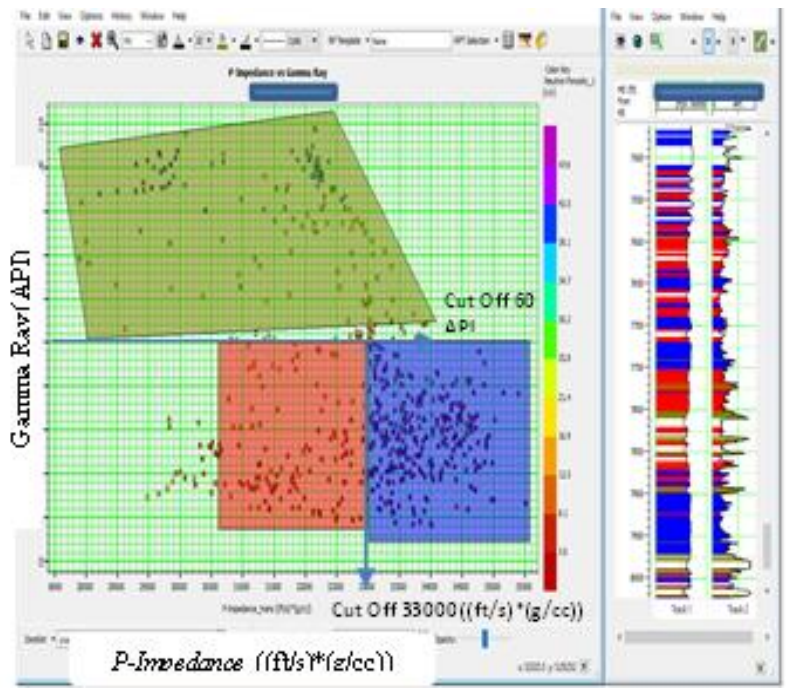

Gambar 4. Cross Plot Gamma Ray \& P-Impedance Sumur Ngawen 1.

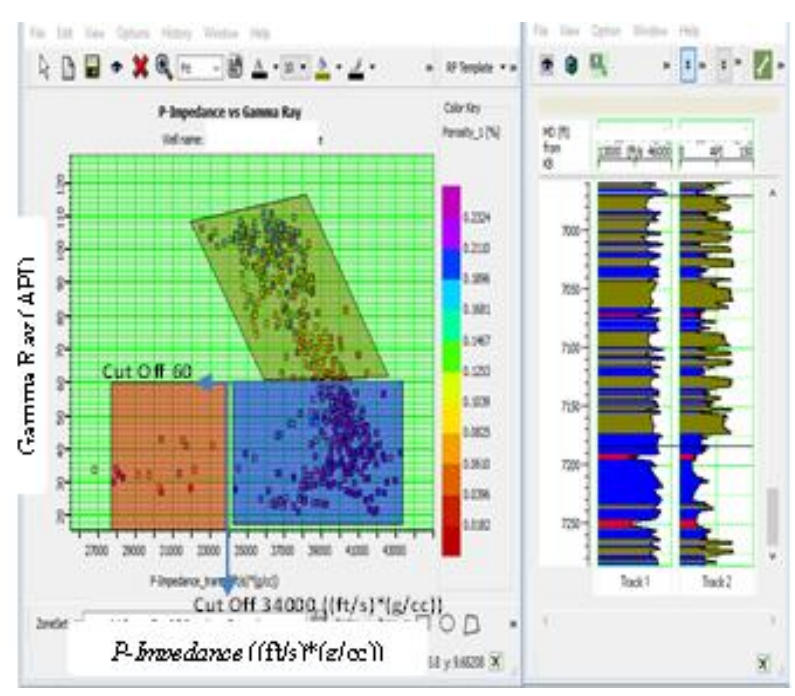

Gambar 5. Cross Plot Gamma Ray \& P-Impedance Sumur Ngawen 2.

Gambar 5 merupakan hasil crossplot antara Gamma Ray dengan P-Impedance pada sumur Ngawen 2. Pada Gambar 5 di atas, batuan shale disimbolkan dengan warna hijau, dengan nilai Gamma Ray tinggi (cut off $>60 \mathrm{API}$ ), karena zona tersebut memiliki nilai porositas yang sangat tinggi. Sedangkan batuan karbonat memiliki nilai Gamma Ray yang rendah (cut off $<60 \mathrm{API}$ ). Batuan karbonat sendiri diklasifikasikan menjadi 2, yaitu batuan tight carbonate dan batuan porous carbonate. Batuan tight carbonate disimbolkan dengan warna biru, yang memiliki nilai $P$-Impedance tinggi yaitu $>34000$ $\left((\mathrm{ft} / \mathrm{s})^{*}(\mathrm{~g} / \mathrm{cc})\right)$, serta nilai porositas yang rendah. Dan batuan porous carbonate disimbolkan dengan warna merah, yang memiliki nilai $P$-Impedance yang relatif rendah yaitu antara 28000-34000 $\left((\mathrm{ft} / \mathrm{s})^{*}(\mathrm{~g} / \mathrm{cc})\right)$, serta nilai porositas yang relatif tinggi dari pada batuan tight carbonate. Nilai $P$-Impedance $34000\left((\mathrm{ft} / \mathrm{s})^{*}(\mathrm{~g} / \mathrm{cc})\right)$ merupakan nilai cut off atau nilai pembatas yang bisa dijadikan pembeda untuk batuan tight carbonate dengan porous carbonate, karena pada nilai tersebut terlihat perbedaan nilai porositasnya.

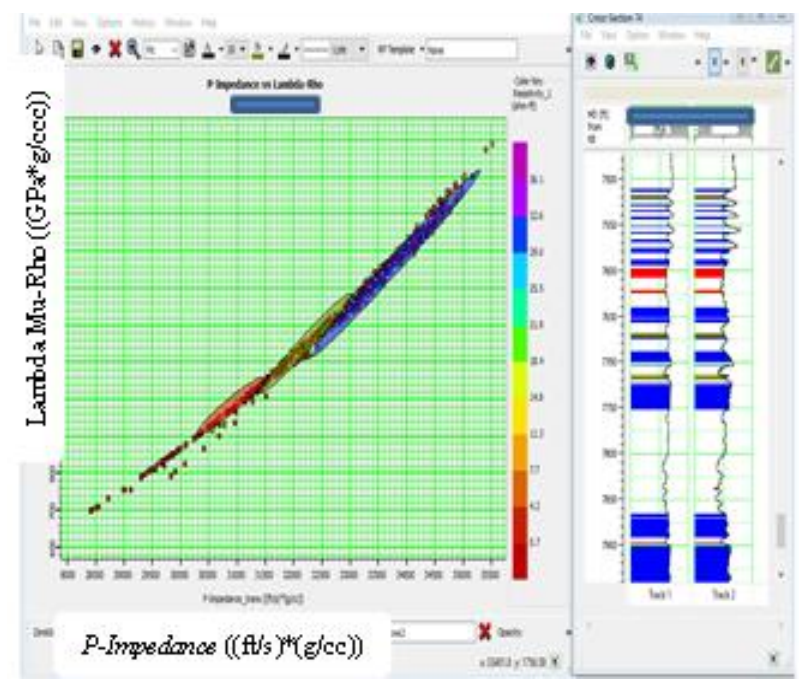

Gambar 6. Crossplot Lambda Mu-Rho \& P-Impedance Sumur Ngawen 1.

Gambar 6 merupakan crossplot antara Lambda Mu-Rho (LMR) dan P-Impedance pada sumur Ngawen 1. Dan Gambar 7 merupakan crossplot antara Lambda Mu-Rho (LMR) dan P-Impedance pada sumur Ngawen 2. Dari Gambar 6 dan Gambar 7 tersebut, fluida gas (zona warna merah) memiliki nilai $P$-Impedance dan LMR yang lebih rendah dari pada fluida oil (zona warna hijau). Fluida oil memiliki nilai LMR dan P-Impedance yang lebih rendah dari pada fluida water. Hal tersebut terjadi karena fluida gas memiliki densitas yang lebih rendah dari pada densitas oil, dan oil memiliki densitas yang lebih rendah dari pada densitas water. Sebab impedance terbentuk dari hasil perkalian antara densitas dan velocity. Dari hasil crossplot ini dapat disimpulkan bahwa parameter Lambda Mu-Rho (LMR) dan PImpedance cukup baik dalam memisahkan daerah target (gas, oil, dan water). 


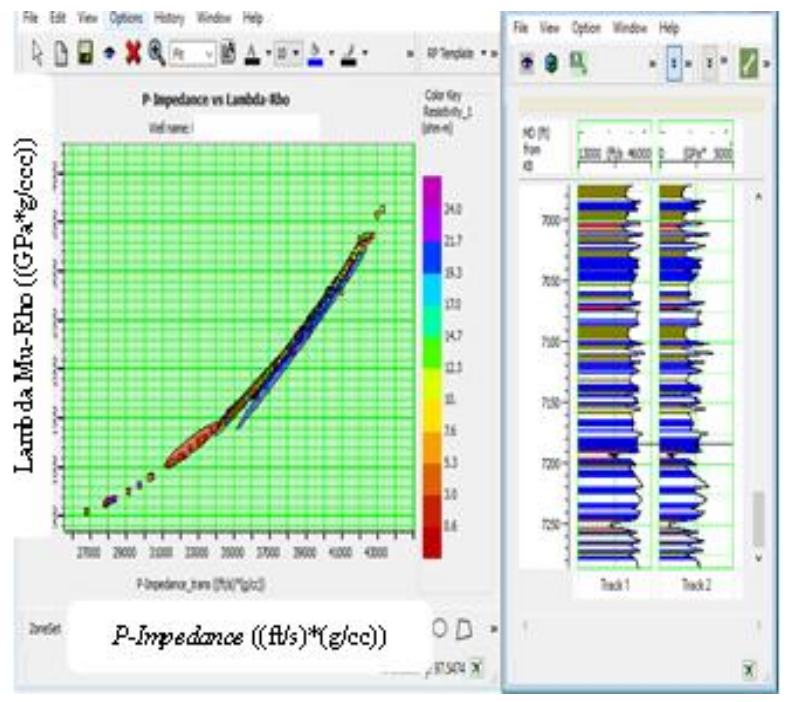

Gambar 7. Crossplot Lambda Mu-Rho \& P-Impedance Sumur Ngawen 2.

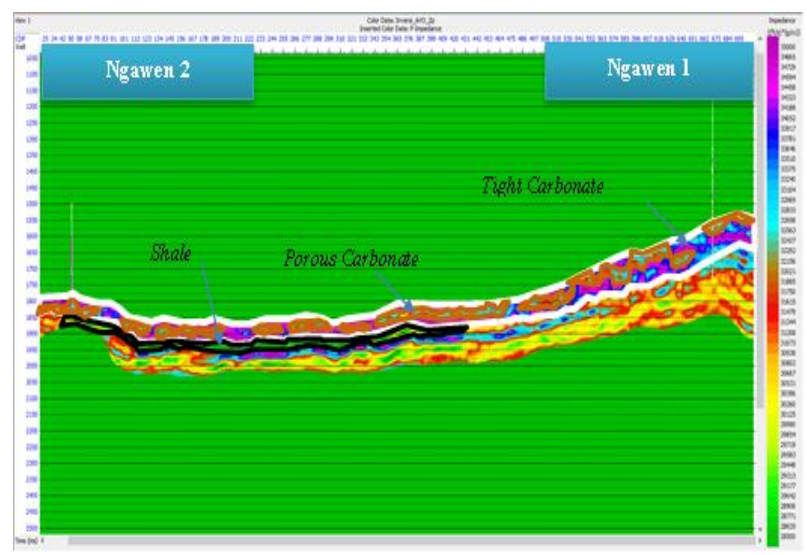

Gambar 8. Hasil Penampang Zp yang Sudah Diinterpretasi.

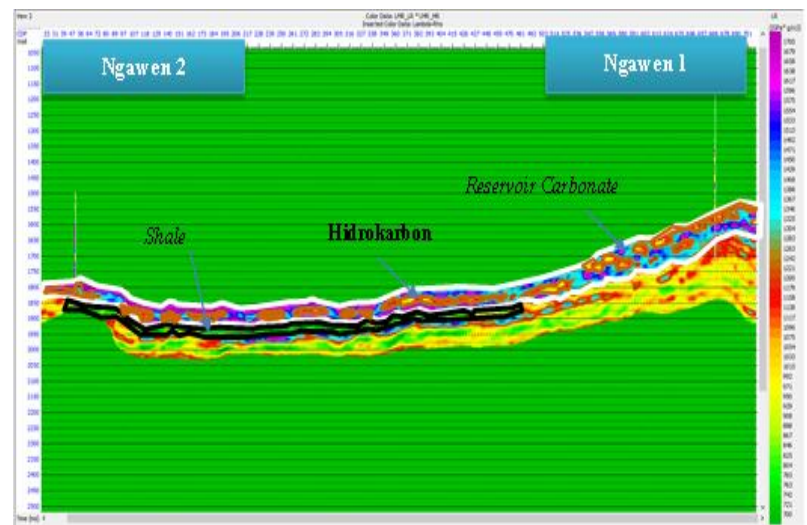

Gambar 9. Penampang Lambda Mu-Rho (LMR).
Gambar 8 merupakan penampang hasil inversi Zp yang sudah diinterpretasi, yang memiliki arah North East - South West. Penampang Zp ( $P$ Impedance) hasil dari inversi tersebut bisa diketahui persebaran litologi pada Formasi Ngimbang Karbonat. Litologi yang dimaksud yaitu batuan Shale, Tight Carbonate, dan Porous Carbonate. Pada Gambar 8 persebaran batuan Shale berada di dalam zona warna hitam, yang memiliki nilai $P$-Impedance sangat rendah yaitu kurang dari 29448 $\left((\mathrm{ft} / \mathrm{s})^{*}(\mathrm{~g} / \mathrm{cc})\right)$. Persebaran batuan Tight Carbonate berada di dalam zona warna putih, yang memiliki nilai $P$-Impedance sangat tinggi yaitu lebih dari $32700\left((\mathrm{ft} / \mathrm{s})^{*}(\mathrm{~g} / \mathrm{cc})\right)$. Persebaran batuan Porous Carbonate berada di dalam zona warna coklat, yang memiliki nilai $P$-Impedance lebih rendah dari pada nilai P-Impedance batuan Tight carbonate, yaitu antara 30200 sampai $32700\left((\mathrm{ft} / \mathrm{s})^{*}(\mathrm{~g} / \mathrm{cc})\right)$. Hasil inversi Zp yang ditunjukkan pada Gambar 8 selaras dengan hasil crossplot antara log Gamma Ray dan $P$ Impedance.

AVO inversi juga menghasilkan penampang LMR (Lambda Mu-Rho), Gambar 9, yang memiliki arah penampang North East-South West. Lambda-Rho sendiri merupakan hasil perkalian antara $\lambda$ dengan $\rho$ atau dikenal dengan Lambda-Rho $(\lambda \rho)$, yang dapat mengindikasikan keberadaan fluida. Inkompresibilitas $(\lambda)$ merupakan tingkat ketahanan suatu batuan terhadap gaya tekan yang mengenainya. Semakin mudah dikompresi maka semakin kecil nilai inkompresibilitas begitu pula sebaliknya. Perubahan ini lebih disebabkan oleh adanya perubahan pori. Batuan yang berisi gas akan memiliki nilai Lambda-Rho yang kecil. Sedangkan Mu-Rho merupakan hasil perkalian antara $\mu$ dengan $\rho$ atau dikenal dengan Mu-Rho. Rigiditas $(\mu)$ atau modulus geser didefinisikan sebagai resistensi batuan terhadap sebuah strain yang mengakibatkan perubahan bentuk tanpa merubah volume total dari batuan tersebut. Rigiditas sensitif terhadap matriks batuan. Semakin rapat matriks batuan, maka batuan tersebut dikatakan memiliki rigiditas yang tinggi.

Hasil penampang LMR (Gambar 9) bisa diketahui persebaran litologi (Shale dan Reservoir carbonete) dan fluida hidrokarbon yang terkandung dalam 
reservoir karbonat pada formasi Ngimbang di lapangan Ngawen. Pada Gambar 9, persebaran batuan shale berada di dalam zona warna hitam, yang memiliki nilai LMR kurang dari 825 (Gpa*g/cc). Persebaran reservoir karbonat berada di dalam zona warna putih, yang memiliki nilai LMR lebih dari 1325 (Gpa*g/cc). Persebaran hidrokarbon berada di dalam zona warna coklat, yang memiliki nilai LMR 908 sampai 1242 (Gpa*g/cc). Hasil tersebut selaras dengan hasil crossplot antara LMR dan P-Impedance fluida hidrokarbon memiliki nilai LMR yang rendah, karena memiliki nilai incompresibilitas yang kecil (mudah dikenai gaya tekan) sehingga nilai LambdaRho $(\lambda \rho)$ yang kecil pula. Dan memiliki nilai rigiditas yang tinggi (nilai $\mu \rho$ tinggi), kerena pada penelitian ini reservoirnya berupa batuan karbonat. Sehingga nilai LMR nya relatif kecil. Sedangkan batuan reservoir karbonat memiliki nilai LMR yang tinggi, karena batuan karbonat memiliki nilai inkompresibilitas dan nilai rigiditas yang tinggi.

\section{PENUTUP}

\section{Simpulan}

Dari hasil penelitian ini, maka dapat ditarik kesimpulan yaitu Karakterisasi reservoir karbonat pada lapangan Ngawen memiliki nilai P-Impedance dan nilai LMR yang relatif tinggi. Sedangkan reservoir karbonat yang mengandung hidrokarbon memiliki karakteristik yaitu nilai $P$-Impedance dan nilai LMR yang lebih rendah.

Persebaran reservoir karbonat di lapangan Ngawen dapat dilihat dari nilai LMR yaitu lebih dari 1325 (Gpa*g/cc).

Persebaran hidrokarbon pada reservoir karbonat di lapangan Ngawen dapat dilihat dari nilai LMR yaitu antara 908 sampai 1242 (Gpa*g/cc).

\section{Saran}

Setelah dilakukan penelitian dan melihat hasil yang didapat, maka saran untuk penelitian lebih lanjut yaitu diperlukan data sumur yang lebih banyak dan tersebar agar dapat memberikan informasi persebaran gas karbonat yang lebih luas di Lapangan Ngawen.

\section{Ucapan Terima Kasih}

Penulis menggucapkan terimakasih kepada Dr.

Dwa Desa Warnana dan Farid Marianto,S.Si selaku pembimbing yang telah meluangkan banyak waktu untuk memberikan bimbingan dan arahan kepada penulis.

\section{DAFTAR PUSTAKA}

Diky Setiawan, Marianto, F., Wikanswasti, D., \& Wardhana, A. (2015). Tuban Sandstone. Indonesian Petroleum Association. Jakarta.

Gray, D., \& Andersen, A. (2001). The Aplication of AVO and Inversion to the Estimation of Rock Properties. CSEG Recorder.

Hampson, D., \& Russel, B. (2008). AVO Workshop Part 1. Cource Notes, CGG Veritas.G. O. Young, "Synthetic structure of industrial plastics (Book style with paper title and editor)," in Plastics, 2nd ed. Vol. 3, J. Peters, Ed. New York: McGraw-Hill (1964) 15-64. 